Conclusions We have instituted a series of measures to increase awareness of infection and sepsis in Trisomy 21, and to reduce the risk of serious bacterial infection. This is in direct response to local data on the causes of mortality in Trisomy 21 in our centre. Whilst it is too early to assess the results of the implemented measures, our experience shows that a multifaceted, multi-departmental approach to reducing risk of mortality can be implemented.

\section{G268 THE JAMES LIND ALLIANCE AND CYSTIC FIBROSIS: A JOURNEY TOWARDS CO-PRODUCTION OF RESEARCH}

${ }^{1}$ NJ Rowbotham, ${ }^{1}$ S J Smith, ${ }^{2}$ ZC Elliott, ${ }^{1}$ AR Smyth. ${ }^{1}$ Evidence Based Child Health, Div. Child Health, Obstetrics and Gynaecology, University of Nottingham, Nottingham, UK; ${ }^{2}$ Parent of Children with Cystic Fibrosis, Nottingham, UK

10.1136/archdischild-2020-rcpch.232

Cystic Fibrosis (CF) is the commonest life limiting inherited condition in the UK, affecting 3895 children. Children with $\mathrm{CF}$ undertake burdensome, time-consuming treatment, much of which is not evidence-based. Questions for clinical research should reflect patient and clinician priorities because both the number of potential participants and funding are limited.

Aims We describe our work over a 4 year period to engage the CF community in prioritisation and co-production of clinical research.

Methods In 2016-17 we undertook a James Lind Alliance (JLA) Priority Setting Partnership (PSP) to find the top 10 priorities for clinical research in CF. Through a series of surveys and workshops these were agreed in conjunction with the global CF community. In 2018-2019 we undertook further global surveys to explore 4 of the top 10 questions in more depth (treatment burden, gastrointestinal symptoms, adherence and exercise in place of some airway clearance). To avoid cross-infection and increase global reach, we adapted JLA methodology to use video conferencing and social media.

Results During the past four years we have gathered opinions from 3729 respondents across six continents. Our youngest respondents were six years old and the median age of respondents with CF (answering directly or by proxy) was 15 years. On completion we disseminated the top 10 questions widely and worked to raise awareness with research funders such as the NIHR. This has resulted in two NIHR themed calls, featuring many of the JLA CF top 10 questions.

Conclusions Encouraging patient participation, including children, in all stages of evidence-based medicine is vital to ensure clinical research is of good quality and relevant to patient needs.

\section{G269 CHAMPIONING THE EX-PRETERM CHILD AT SCHOOL}

FE Payne, AM Oliver. Community Paediatrics, Barnsley Hospital, Barnsley, UK

10.1136/archdischild-2020-rcpch.233

Aims Children born prematurely are more likely to experience health, educational and social difficulties compared to matched term peers. Educational professionals lack relevant knowledge and feel unprepared to support them.

This project evaluates local Special Educational Needs Coordinators (SENCOs) existing knowledge; develops and delivers a teaching package, and evaluates the effectiveness of this resource.

Method

- Initial survey developed and sent to all local primary school SENCOs.

- Teaching package developed.

- Teaching revised based on SENCOs and educational psychologist focus group feedback.

- Prematurity teaching package delivered to the regional Newly Qualified Teachers training.

- Post-teaching survey distributed and analysed.

Results

- $27 \%(22 / 77)$ of SENCOs completed the initial survey.

- $86 \%$ reported little/no previous training.

- $86 \%$ reported limited/no knowledge of the education and social effects.

- $67 \%$ reported school had no process for routinely identifying ex-preterms.

- Qualitative data, in response to 'improving health and education working':

- $12 / 33$ responses requested 'training about prematurity effects' ( $95 \%$ felt face to face with/without written format would be optimal).

- The final teaching package was delivered to 37 teachers.

- Post-teaching survey showed an improvement in perceived: educational difficulties - 28/37 rated their knowledge after as good/excellent compared to $5 / 37$ before social difficulties $30 / 37$ rating their knowledge after as good/excellent compared to $5 / 37$ before $95 \%$ felt the teaching was

- 'useful'/'very useful'.

- $100 \%$ reported it would change their future approach. The most common thematic responses included 'identifying', 'asking parents' and 'providing support'.

- 95\% reported preference for face-to-face training over electronic. 'Questions', 'explanations' and 'engaging' were the most common qualitative themes.

- Feasibility to attend training was variable. 54\% reported 'easy'/'very easy', 38\% 'difficult'/'very difficult' and 8\% left unanswered.

Conclusion The results of the SENCOs previous training and knowledge of prematurity survey are similar to national research and demonstrated a local training need. ${ }^{1}$

The teaching package was positively received and produced a perceived improvement in knowledge with intended change to future practice to the benefit of local children born prematurely. Study limitations of small numbers and subjective assessment acknowledged and considered for future work.

\section{REFERENCES}

1. Johnson, et al. The long-term consequences of preterm birth: what do teachers know? Developmental Medicine and Child Neurology 2015; 57:571-577

\section{G270 DQ TYPING FOR DOWN SYNDROME SHOULD BE PART OF ROUTINE SURVEILLANCE}

1J Yates, ${ }^{2} P$ Gillett. 'Community Paediatrics, St. John's Hospital, Livingston, UK; ${ }^{2}$ Paediatric Gastroenterology, Royal Hospital of Sick Children, Edinburgh, Edinburgh, UK

10.1136/archdischild-2020-rcpch.234 